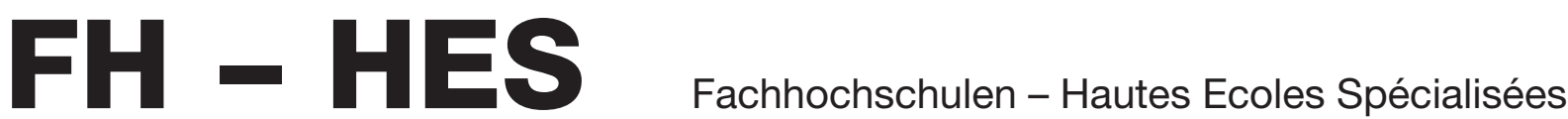

\section{New Versatile Multipurpose Reactor}

\author{
Men F. Barblan* and Fred Steinegger
}

\begin{abstract}
A new batch process facility at the University of Applied Sciences Basel, Switzerland, is not only multipurpose in the chemical sense but also in regard to its application in education and for R\&D. In addition to being utilized in the teaching of regular student courses as well as in courses with external participants, it will be regularly used to produce basic chemical building blocks to order and will serve as a test facility for further development of 'Key Performance Indicators'.
\end{abstract}

Keywords: Chemical engineering · Customer synthesis · Education · Key Performance Indicators . University of Applied Sciences Basel

\section{Introduction}

The laboratory facilities of a university are in general not continually needed for educational purposes due to the extended periods without lab activities between terms. Thus - especially in the case of very cost-intensive installations - other applications must be sought. Our new multipurpose batch process facility is a good example of how a unit can be put to multiple use. Generally the expression 'multipurpose' is thought to apply only to products and processes. However it can as in our case - be extended to include different usages altogether. Our plant serves the following purposes:

- training of regular students of the chemistry and mechanical engineering departments

- training of external personnel with various backgrounds and interests

- production of basic chemical building blocks to order (in our case for a startup company)
- as a model reactor and study object for the development and testing of advanced process indicators, which we call 'Key Performance Indicators' (KPI)

\section{Facilities}

The Center for Chemical Engineering [1] of the University of Applied Sciences Basel already possesses several reactor units in sizes between 50 and 250 liters. To these a multipurpose system is now being added consisting of a 400 liter glass-lined reactor [2] with a distillation column [3] of $200 \mathrm{~mm}$ diameter for corrosive products and fitted with a heating/ cooling system permitting operation between $-20^{\circ} \mathrm{C}$ and $+150^{\circ} \mathrm{C}$ (Fig. 1 and 2). The engineering and construction as well as the programming of the process control system is being accomplished with our own personnel: Daniel Mollet (Process and Project Engineer), Hugo Briellmann (Pilot Plant Operations), and Horst Brauchart (Assistance). The start-up will take place in the middle of 2002.

\section{Use in Education}

Department of Chemistry

University of Applied Sciences Base

Gruendenstrasse 40

$\mathrm{CH}-4132$ Muttenz

Tel.: +41614674348

Fax: +41614674457

E-Mail: m.barblan@fhbb.ch

www.fhbb.ch/chemie
The curricula in the Departments of Chemistry and Mechanical Engineering include piloting of mechanical and thermal processes (chemists in the 5th semes- ter, process engineers in the 6th semester). Subjects which can be covered with the new facility are the unit operations distillation [4] and rectification as well as the study of heat transport phenomena through the reactor wall. A typical procedure is to precalculate and predict behavior on a theoretical basis, then to do the piloting and afterwards to analyze results and discuss divergence from the expected values.

In the 6th semester ongoing chemists learn to scale-up reactions and carry them out on a pilot scale in the Center for Chemical Engineering. They are taught to go through all planning and production phases starting with the production schedule then writing the operation procedure, doing a risk analysis, carrying out the production itself and ending with a process documentation, which is up to industrial standards.

\section{Courses for Industry}

On several occasions in recent years the staff of the Center for Chemical Engineering has been asked to give introductory courses in chemical engineering and process control for companies doing business with the process industries (i.e. Siemens Ltd, Endress \& Hauser Ltd). The contents of the courses, which were individually structured, included basic theory, the reading of process flow dia- 


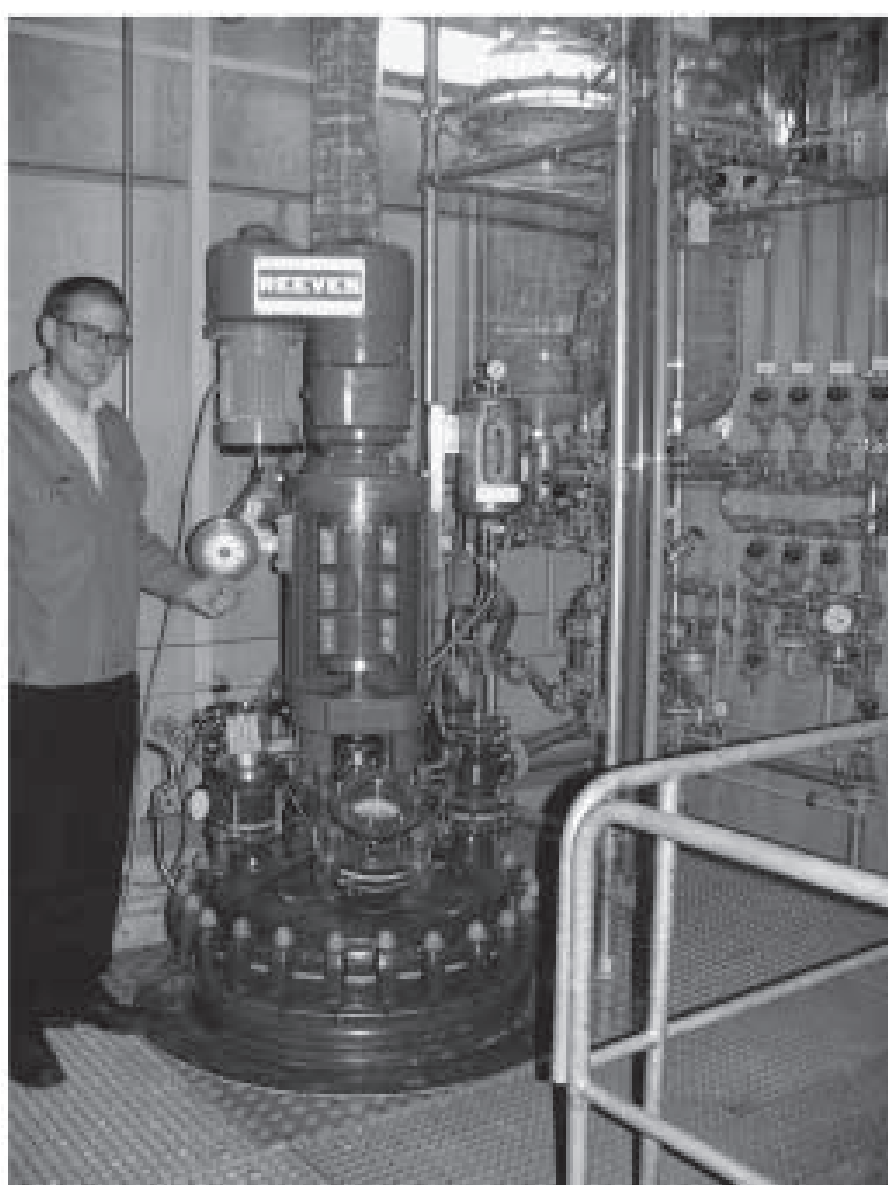

Fig. 1. The new $400 \mathrm{I}$ glass-lined multipurpose reactor with heating/ cooling system $\left(-20\right.$ to $\left.+150^{\circ} \mathrm{C}\right)$

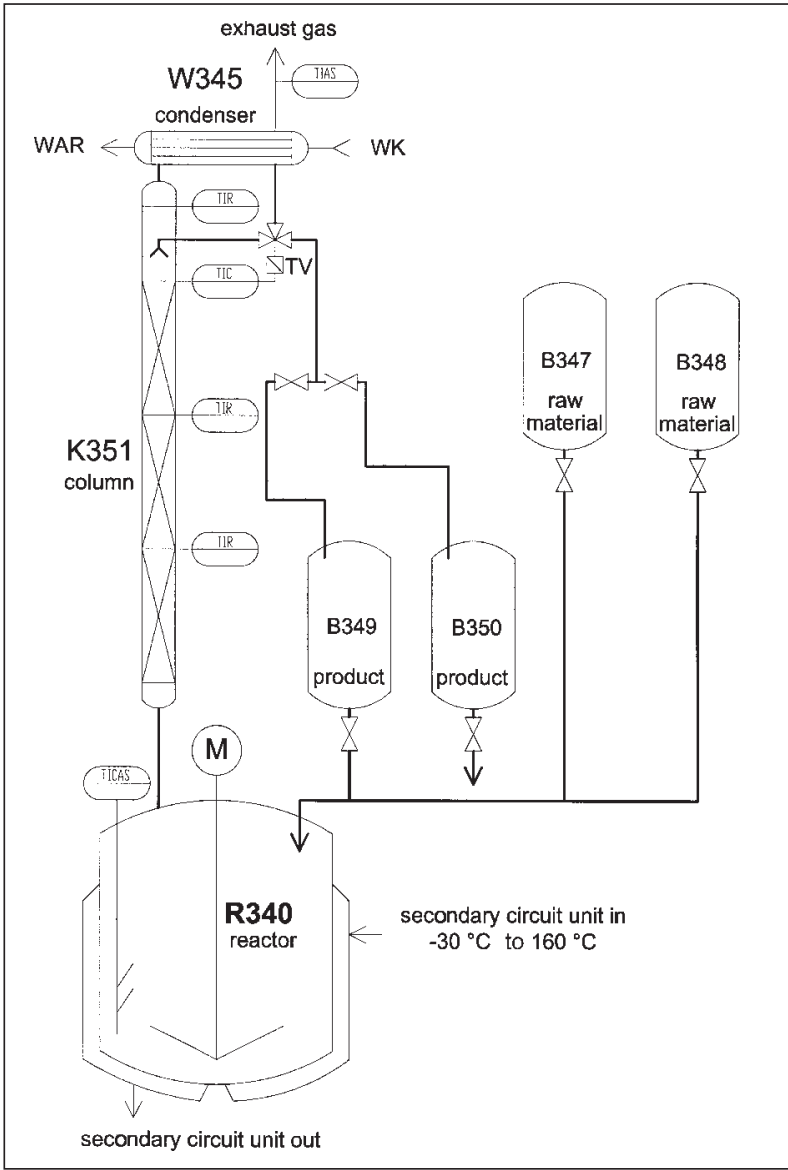

Fig. 2. Flow sheet of the 400 I multipurpose facility grams and ending with actually operating a production unit with integrated process control. In future courses, the new multipurpose plant will be an additional asset.

\section{Commercial Applications}

Another main area of interest are commercial production services for external customers, where the new unit will play an important role. Piloting and production of stereo-selective key components by means of bio-transformation has in the past been a rewarding field using 100-400 1 bioreactors and producing on a $\mathrm{kg}$ scale. The new unit is ideally suited for purification of such products and for solvent recovery. Furthermore it will be used to produce synthetic building blocks for SynphaBase Ltd. - a new start-up company at the University of Applied Sciences Basel.

\section{Applied R\&D}

Object of a recent research project (Project LEAN-Maintenance [5][6] /KTI No. 4301.1/CHF 573'453) was the online calculation and trending of relevant factors to keep track of plant performance. As a result it was possible to extrapolate the deadline for a maintenance shutdown of a key reaction in the production of vitamin $\mathrm{A}$ and thus replace frequent periodic maintenance with maintenance on demand saving unnecessary expenditures. Meanwhile the reliability of the process model and the indicator in use has been proven on a long-term basis.

At this time the application of the method to gain more meaningful information on overall process status than by trending of control data alone is being studied, so that operating personnel and supervision will have better control over plant operations.

With these 'Key Performance Indicators' (KPI) it should be possible to improve quality and/or quantity of a product, reduce costs, make the process safer by, for example, detecting the accumulation of reactants in a reaction, and optimize process conditions which cannot be measured directly. For this purpose KPI are continually and automatically calculated from control data without any additional effort on the part of the operating personnel and are displayed separately in a Management Information System (MIS). Possible KPI will be implemented in the new multipurpose unit and extensively tested, i.e. the automatic output of on-line mass- and energy balances and the monitoring of reactions regarding accumulation and potential of destruction.

Received: February 26, 2002

[1] M. Barblan, E. Hungerbühler, Chimia 1994, 48, 524.

[2] Donated by Novartis Pharma AG, Basel.

[3] Donated by SIBAG AG, Emmenbrück.

[4] M. Barblan, F. Steinegger, Chimia 1995, 49 , 309.

[5] J. Kopainsky, U. Herr, P. Henzmann, Schweizerische Technische Zeitschrift 1999, 3,30 .

[6] Siemens Schweiz AG, Internal Publication: Lean Maintenance. 